\title{
吉林蛟河不同演替阶段针阔混交林乔木幼苗数量 组成及其时间动态
}

\section{间琰 张新娜 姚 杰 张春雨 赵秀海*}

北京林业大学森林资源与生态系统过程北京市重点实验室, 北京 100083

摘 要 为了解蛟河地区木本植物幼苗的数量特征及其年际动态, 以及影响幼苗数量的生态学过程, 该文以不同演替阶段针 阔混交林监测样地为基础, 在样地内共设置了 451个种子雨-幼苗观测样站。通过2012-2014年连续3年的幼苗监测调查, 对木 本植物幼苗物种组成、数量特征、高度级结构及其年际动态进行了分析, 并用多元回归的方法分析了幼苗数量与林分类型、 同种成体胸高断面积之和及林冠开阔度的关系。结果表明: (1)林下幼苗层主要木本植物的组成在不同演替阶段林分中差异不 大, 并与样地内主要树种组成保持着一定相似性, 但幼苗重要值排序在年际间和不同演替阶段稍有波动。(2) 3 个样地内幼苗 个体数量和物种数都主要集中在 $5-20 \mathrm{~cm}$ 高度级之间, 之后随高度级增加而逐渐减少, 但幼苗个体数量减少更快。表明与种间 竞争相比, 物种内部的相互作用是导致幼苗死亡的主要原因, 证实了负密度制约效应在幼苗更新过程中的作用。(3) 5 个主要 树种的幼苗数量都与同种成体胸高断面积之和呈显著的正相关关系, 还呈现出明显的生境偏好, 表明扩散限制和生态位过程 也会影响幼苗的数量和分布。该文间接证实了负密度制约效应、扩散限制和生态位过程对温带地区不同演替阶段森林群落中 幼苗数量组成的影响。

关键词 幼苗组成; 演替阶段; 负密度制约; 扩散限制; 生态位

引用格式: 间琰, 张新娜, 姚杰, 张春雨, 赵秀海 (2016). 吉林蛟河不同演替阶段针阔混交林乔木幼苗数量组成及其时间动态. 植物生态学报, 40, 127-139. doi: 10.17521/cjpe.2015.0365

\section{Composition and temporal dynamics of tree seedlings at different successional stages of coni- fer and broad-leaved mixed forests in Jiaohe, Jilin Province, China}

YAN Yan, ZHANG Xin-Na, YAO Jie, ZHANG Chun-Yu, and ZHAO Xiu-Hai*

Key Laboratory for Forest Resources \& Ecosystem Processes of Beijing, Beijing Forestry University, Beijing 100083, China

\section{Abstract}

Aims Our objective was to explore the composition and temporal dynamics of woody plant seedlings and the ecological processes that affect the amount of seedlings in Jiaohe, Jilin Province, China.

Methods We established a total of 415 seed-seedling census stations in three large permanent field plots belonging to three successional stages in the conifer and broad-leaved mixed forests. Based on three seedling censuses from 2012 to 2014, we analyzed species composition, quantitative character, height-classes structure and their inter-annual dynamics. Multiple linear regression was used to test the relationship between the abundance of seedlings for five major species and the forest types, the sum of the basal area of conspecific adult within 20 m away from a seed trap, as well as canopy openness.

Important findings Our results show that: (1) The species composition of seedlings slightly varied among different successional stages, and was similar with that of trees in the plots. The rank of important values for seedling species among different years and successional stages varied slightly. (2) The number of seedlings and seedling species distributed mainly between 5-20 cm height classes, and decreased with the increasing height class. The number of seedlings decreased faster than that of seedling species, indicating that compared with interspecific competition, intraspecific competition was the main driver that led to seedling death. It confirmed the role of the negative density dependence in affecting seedling regeneration. (3) The amount of seedlings for all of the five major species was significantly positively related to the sum of the basal area of conspecific adults, which indicated that the quantity and distribution of seedlings were affected by dispersal limitation as well as niche

收稿日期Received: 2015-10-13 接受日期Accepted: 2015-12-27

* 通信作者Author for correspondence (E-mail: zhaoxh@bjfu.edu.cn) 
processes. Our research confirmed the role of negative density dependence, dispersal limitation and niche processes on seedling composition.

Key words seedling composition; successional stage; negative density-dependence; dispersal limitation; niche processes

Citation: Yan Y, Zhang XN, Yao J, Zhang CY, Zhao XH (2016). Composition and temporal dynamics of tree seedlings at different successional stages of conifer and broad-leaved mixed forests in Jiaohe, Jilin Province, China. Chinese Journal of Plant Ecology, 40, 127-139. doi: 10.17521/cjpe.2015.0365

森林天然更新是一个持久而复杂的生态学过程 (Szwagrzyk et al., 2001; 尹华军等, 2011), 是森林群 落演替与植被生态恢复的关键(李帅锋等, 2008)。在 更新过程中, 以木本植物为主的生物种群在时间和 空间上不断扩大、扩散和延续(苏嫄等, 2014), 对未 来植物群落的组成、结构、分布与演替格局产生深 远影响(D’Amato et al., 2009; 于飞等, 2013)。因此, 深入理解木本植物幼苗的组成、结构、存活和生长 规律及幼苗更新的限制因子是森林生态系统经营管 理和生物多样性保护的基础(张健等, 2009)。

影响幼苗更新的因素有很多, 可以分为生物因 素和环境因素。首先, 充足的种源是保证森林更新 的物质前提和基础(郭秋菊, 2013), 但由于种子传播 方式不同, 种子雨和幼苗的相似性可能存在较大差 异。Teegalapalli等(2010)对印度季节性干旱热带森 林的研究表明, 尽管风力传播的种子在数量上远远 大于脊椎动物传播的种子, 但脊椎动物传播物种的 幼苗多度远大于风力传播的物种。其次, 不同类型 的林分在树种组成、年龄结构、空间分布和立地条 件等方面有很大差异, 树种更新状况也不尽相同。 康冰等(2011)研究了秦岭山地 5 种典型次生林幼苗 的更新特征, 发现在不同林分中幼苗物种分化明显, 且幼苗和幼树所占比例存在明显差异。此外, 植物 的化学他感作用、病原体和动物捕食也对幼苗更新 有很大影响(Nilsen et al., 1999; 彭闪江等, 2004; Clark et al., 2012)。如Janzen (1970)和Connell (1971) 提出了负密度制约效应假说, 他们认为在同种个体 密度较高的区域, 物种特异性天敌(如病原体、食草 动物)会降低幼苗的存活率、生长率和更新率, 从而 给予其他物种生存的空间和资源, 维持了群落物种 多样性。这一生态学过程已在热带森林、亚热带森 林和温带森林中得到了很好的验证(Chen et al., 2010; Jansen et al., 2014; Yan et al., 2015)。

除了生物因素, 林下木本植物幼苗更新还受到 立地条件、光照、水分和土壤养分等环境因素的影
响。苏嫄等(2014)对黄土丘陵沟壑区坡沟不同立地 环境下的幼苗密度和幼苗存活率进行了分析, 结果 发现阳坡幼苗密度较小而存活率较高, 阴坡幼苗密 度较大但存活率较低; 同一物种在不同立地环境下 表现出不同的存活曲线, 不同物种在不同立地环境 下也可呈现同一存活曲线。王传华等(2011)研究发 现, 在3\%透光率下一年生枫香树 (Liquidambar formosana)苗的死亡率接近 $90 \%$, 并认为良好的光照 条件是枫香树成功更新的必要条件。而Szwagrzyk 等(2001)认为长期的幼苗存活也与光照强度有很大 关系。Comita等(2009)对受县风影响后的热带森林 研究发现, 林冠开阔度是影响幼苗存活的一个主要 驱动因素。Lin等(2012)在西双版纳热带季雨林的研 究表明, 受干旱胁迫的影响, 由负密度制约导致的 幼苗死亡在旱季比在雨季更为强烈。

木本植物幼苗数量特征、更新策略及影响因素 在群落演替的不同阶段差异较大, 其更新特征很大 程度上决定着群落的演替方向与恢复的可能性(俞 䈗押和李玉辉, 2010)。尽管近年来国内外学者已对 林下幼苗层更新动态及其影响因素展开了大量研究, 但大多集中于单一群落类型(Harms et al., 2000; 李 媛等, 2007; 尚占环等, 2008; Rüger et al., 2009; Teegalapalli et al., 2010; Willand et al., 2013; Jansen et al., 2014; Lebrija-Trejos et al., 2014; 姚杰等, 2015), 有关演替阶段对幼苗更新影响的研究还比 较少(李小双等, 2009; 俞篖押和李玉辉, 2010; Chen et al., 2011; 康冰等, 2011)。

本文以吉林省蛟河地区不同演替阶段针阔混交 林群落内的木本植物幼苗为研究对象, 基于 2012-2014年连续3年的幼苗调查数据, 对木本幼苗 的组成及其年际动态进行分析, 旨在: (1)分析木本 植物幼苗组成及其在时间上的动态变化规律; (2) 探讨幼苗更新的影响因素及其在不同演替阶段的差 异。试图阐述幼苗增补与环境因素、扩散限制以及 负密度制约效应的关系, 为温带森林生态恢复提供 
理论依据和数据支撑。

\section{1 研究地概况和研究方法}

\section{1 研究区概况}

研究地位于吉林省蛟河林业试验区管理局林场 $\left(43.85^{\circ}-44.08^{\circ} \mathrm{N}, 127.58^{\circ}-127.85^{\circ} \mathrm{E}\right)$, 总经营面积 $31823 \mathrm{hm}^{2}$ 。该地区属长白山脉张广才岭, 最高海拔 $1176 \mathrm{~m}$, 最低海拔仅 $330 \mathrm{~m}$, 相对高差 $846 \mathrm{~m}$ 。该区 域属受季风影响的温带大陆性气候, 年平均气温 $3.8^{\circ} \mathrm{C}$, 最热月7月平均气温为 $21.7{ }^{\circ} \mathrm{C}$, 最冷月 1 月平 均气温为 $-18.6{ }^{\circ} \mathrm{C}$ 。年降水量为 $700-800 \mathrm{~mm}$, 多集 中在6-8月。初霜期多在9月下旬, 终霜期一般在翌 年5月中旬, 无霜期120-150天。平均积雪厚度20-60 $\mathrm{cm}$, 土壤结冻深度 $1.5-2.0 \mathrm{~m}$ 。土壤类型主要为暗棕 色森林土, 土层厚度为20-100 cm。该地区植被属于 长白山植物区系, 植物种类多样分布复杂。主要林 分类型为天然次生针阔混交林, 原始阔叶红松林是 该地区森林的顶级群落类型。乔木建群种主要包括 红松(Pinus koraiensis)、杉松(Abies holophylla)、东 北枫(Acer mandshuricum)、五角枫(Acer pictum subsp. mono)、胡桃楸 (Juglans mandshurica)、水曲柳 (Fraxinus mandschurica)、紫椴(Tilia amurensis)等。

\section{2 样地设置}

根据林分发育阶段和演替特征，2010年夏季在 吉林省蛟河林业实验区管理局林场内, 选取了中龄 林(HF)、成熟林(MF)和老龄林(OGF) 3种类型的林分, 构成一个演替系列。参照CTFS (Center for Tropical Forest Science)样地建设方案(http://www.ctfs.si.edu/), 在每个林分内各建立了一块固定监测样地, 总面积 为93.84 $\mathrm{hm}^{2}$, 样地概况如表1所示。2010年夏季和秋 季, 对样地内所有胸径 $(D B H) \geqslant 1 \mathrm{~cm}$ 的木本植物进 行调查。记录每株植物的种类、胸径、冠幅、活枝
下高和坐标等，并挂牌标记。

\section{3 样地树种组成}

在中龄林样地中, 共监测到木本植物 42 种, 隶 属于17科26属, 重要值前5位的树种分别为胡桃梑、 东北枫、五角枫、春榆(Ulmus davidiana var. japonica) 和水曲柳; 成熟林样地中共监测到木本植物 46种, 隶属于17科 28 属, 重要值前5位的树种分别为五角 枫、千金榆(Carpinus cordata)、东北枫、红松和紫 椴; 老龄林样地中共监测到木本植物 47 种, 隶属于 18 科30属, 重要值前5位的树种分别为五角枫、裂叶 榆(Ulmus laciniata)、千金榆、紫椴和东北枫。

\section{4 幼苗样方设置与调查}

2011年7月采用机械布点的方法, 在各样地内 每隔40 m设置一个种子雨收集器, 中龄林共设置收 集器99个, 成熟林 209 个, 老龄林143个(图1)。自 2012年起，每年7月至10月每隔14天收集一次承接 盘内种子及调落物。将每个收集器内收集到的种子 鉴定到种并记录其数量。每年第一次和最后一次的 收集时间分别为7月15日和10月31日。

以收集器为中心, 在种子收集器的四面距其1 $\mathrm{m}$ 处, 分别设置 4 个 $1 \mathrm{~m} \times 1 \mathrm{~m}$ 的幼苗调查样方, 每个 样方的 4 个角用涂有红油漆的木桩标记。每个收集器 和与之对应的 4 个幼苗小样方构成一个种子雨-幼苗 观测样站(图2)。2012-2014年, 于每年7-8月对所有 样方内的幼苗进行调查, 记录每株幼苗的种名、年 龄、高度和基径, 并挂牌编号, 以便第二年复查时监 测其存活状态(Yan et al., 2015)。

\section{5 数据分析方法}

\subsection{1 幼苗的数量特征}

(1)幼苗重要值

采用相对多度和相对频度来计算各物种的重要 值: 幼苗重要值 $=($ 相对多度 + 相对频度 $) / 2$ 。其中,

表1 吉林蛟河森林永久监测样地概况

Table 1 Summary of permanent forest plots in Jiaohe, Jilin Province, China

\begin{tabular}{|c|c|c|c|c|c|}
\hline 林型 & 样地面积 & 经纬度 & 海拔 & 样站数 & 原始植被 \\
\hline Forest type & Plot area & Longitude and Latitude & Elevation (m) & No. of stations & Primary vegetation \\
\hline 中龄林 & $420 \mathrm{~m} \times 520 \mathrm{~m}$ & $43.97^{\circ} \mathrm{N}, 127.73^{\circ} \mathrm{E}$ & $468-519$ & 99 & 阔叶红松林 \\
\hline Half-mature forest & & & & & Broad-leaved Pinus koraiensis forest \\
\hline 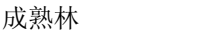 & $500 \mathrm{~m} \times 840 \mathrm{~m}$ & $43.95^{\circ} \mathrm{N}, 127.73^{\circ} \mathrm{E}$ & $459-517$ & 209 & 阔叶红松林 \\
\hline Mature forest & & & & & Broad-leaved Pinus koraiensis forest \\
\hline 老龄林 & $500 \mathrm{~m} \times 600 \mathrm{~m}$ & $43.97^{\circ} \mathrm{N}, 127.75^{\circ} \mathrm{E}$ & $576-784$ & 143 & 阔叶红松林 \\
\hline Old-growth forest & & & & & Broad-leaved Pinus koraiensis forest \\
\hline
\end{tabular}


中龄林 HF

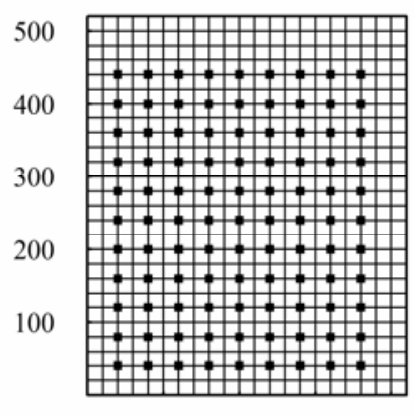

$0 \quad 100 \quad 200 \quad 300 \quad 400$
成熟林 MF

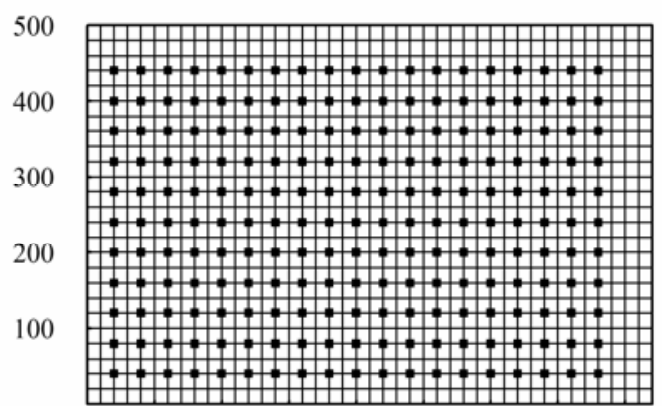

$\begin{array}{lllllllll}0 & 100 & 200 & 300 & 400 & 500 & 600 & 700 & 800\end{array}$

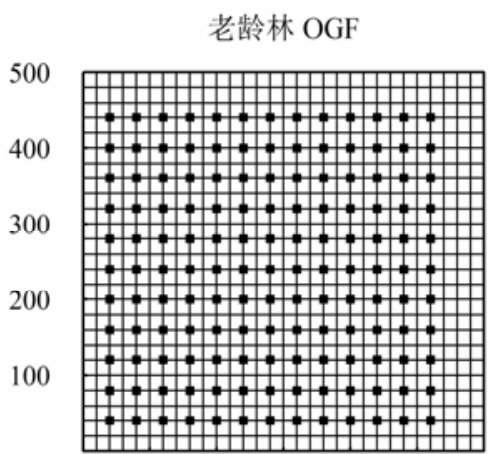

$\begin{array}{lllllll}0 & 100 & 200 & 300 & 400 & 500 & 600\end{array}$

图1 三个样地监测样站分布示意图。

Fig. 1 The layout of monitoring stations in each of three forest plots. HF, half-mature forest; MF, mature forest; OGF, old-growth forest.

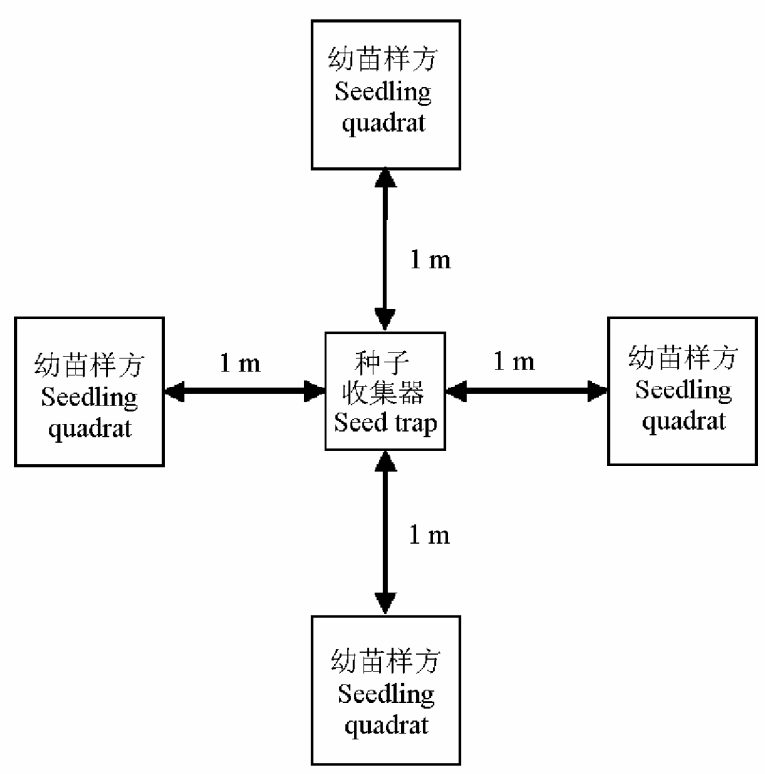

图2 样站幼苗小样方设置示意图。

Fig. 2 Quadrat layout at each of the sampling station.

相对多度 $=($ 某物种的多度/所有种的多度和 $) \times 100 \%$ 相对频度 $=($ 某物种的频度/所有种的频度和 $) \times 100 \%$

(2)幼苗死亡率

幼苗死亡率 $=($ 前一次调查到的幼苗数量 - 后一 次调查到的非新生幼苗数量)/前一次调查到的幼苗 数量 $\times 100 \%$ 。

\subsection{2 高度等级划分}

根据幼苗的高度, 将其划分为不同的高度等级 (cm): 0-5, 5-10, 10-20, 20-30, 30-40, 40-50, 50-60, 60-70, 70-80, 90-100, $\geqslant 100$, 并统计不同高度级相 对多度与丰富度。

\subsection{3 幼苗密度的影响因素}

对五角枫、东北枫和水曲柳等幼苗个体数和出 现样站较多的 5 个树种, 用多元线性回归方法分析 各样站幼苗个数与林分类型、同种成体密度及样站 所在位置的林冠开阔度(canopy openness)的关系。同 种成体密度 $(A)$ 是指以样站中心为圆心、半径 $20 \mathrm{~m}$ 内 $D B H \geqslant 1 \mathrm{~cm}$ 的所有同种个体的胸高断面积除以它 到样站的距离之和, 即:

$$
A=\sum_{i}^{N} B A_{i} / \text { Distance }_{i}
$$

其中, $B A_{i}$ 为第 $i$ 个个体的胸高断面积, Distance $e_{i}$ 为第 $i$ 个个体到样站中心的距离。进行回归分析之前, 先 对各个变量进行数据标准化处理。

于 2012年8月阴天, 用冠层分析仪(WinSCANOPY, Quebec, Canada)在每个样站中心距离地面 $1.5 \mathrm{~m}$ 处拍摄1张半球状照片, 用对应的WinSCANOPY和XLScanopy软件对照片进行处理, 得到林冠 开阔度。

在进行多元回归分析之前, 对所有连续变量进 行数据标准化处理, 并对幼苗数量和同种成体密度 进行 $\log (N+1)$ 转化。本文中所有数据分析与绘图均 采用国际通用软件R-3.2.0 (http://www.r-project.org) 和Microsoft Excel 2010完成。

\section{2 研究结果}

\section{1 幼苗数量与组成}

2012-2014年3次调查期间，在中龄林99个监测 样站内共调查到 18 种木本植物幼苗, 隶属于 10 科 11 
属; 成熟林209个样站内共调查到17个树种的幼苗, 隶属于 9 科 11 属; 老龄林 143 个样站 3 年内均调查到 16 个树种的幼苗，隶属于 9 科10属(表2)。三种林分的 幼苗都是以水曲柳、杉松、五角枫和东北枫为主, 老 龄林中水曲柳的幼苗相对较少。青杨(Populus cathayana)、山杨(Populus davidiana)、稠李(Prunus avium) 和乌苏里鼠李(Rhamnus ussuriensis) 只在中龄 林出现, 蒙古柇(Quercus mongolica)和三花枫(Acer triflorum) 只在成熟林和老龄林中出现, 毛榛 (Corylus mandshurica) 只在成熟林出现。各样地内的 幼苗总数都在2013年达到峰值, 2014年幼苗数量最 少, 不到2013年幼苗数量的一半(表2)。

尽管林下幼苗的主要物种组成在不同林型间差 异不大, 各物种重要值排名在不同群落和年际间稍 有波动(表2)。三次调查期间, 东北枫和五角枫幼苗 始终是3个演替阶段的优势种, 重要值均在前5位。 水曲柳在中龄林和成熟林具有明显的优势地位, 而 在老龄林的重要值仅为5.23-2.92。另外, 3种林分中 杉松和五角枫的重要值在年际间差异很大, 而中龄 林和成熟林中, 东北枫的重要值在年际间差异较大。

\section{2 新生幼苗数量与组成}

2012-2014年间，中龄林内共调查到14种1 729 株新生木本植物幼苗(表2)。五角枫新生幼苗数量最 多, 其次为东北枫、水曲柳和杉松, 幼苗数量均大于 300。而黄檗(Phellodendron amurense)、辽椴(Tilia mandshurica) 和千金榆的新生苗数量均小于 10 。新 生幼苗的数量在年际间存在明显差异: 2013年新生 幼苗总数约为 2012年的 2 倍和 2014年的10倍; 水曲 柳、五角枫、东北枫、紫椴和青楷枫(Acer tegmentosum) 等树种的新生幼苗数量都在2013年出现高峰, 其中五角枫、东北枫、青楷枫和紫椴的出生率均达 到80\%以上; 杉松在2012年出现高峰, 约为2013年 新生苗数量的30倍和2014年新生苗数量的50倍; 红 松在2012年调查到26株新生幼苗, 而在2013年和 2014年仅调查到5株和2株; 黄檗的新生幼苗仅在 2012年出现, 辽椴和千金榆的新生幼苗仅在2013年 出现。

成熟林3年内共调查到5 779株新生木本植物幼 苗, 隶属于16个种(表2)。新生幼苗数量排前 3 位的物 种为: 杉松、五角枫和紫椴, 占总幼苗数的 $69.12 \%$ 。 东北枫、水曲柳、辽椴、青楷枫、红松和千金榆的 新生幼苗数均大于 100 , 而裂叶榆、蒙古柇和黄檗的
新生幼苗数均在10以下。新生幼苗总数在 2013 年达 到峰值, 约为2012年新生幼苗数量的 2 倍和2014年 的4倍。水曲柳和槭树科植物的幼苗都在2013年出现 高峰; 而杉松的新生幼苗数量在2012年出现高峰达 到1 341株, 2012年和2013年新生幼苗数量仅为 3 和 22株。紫椴在2013年和2014年分别调查到420和445 株，而2012年仅调查到63株。

老龄林3次调查期间共发现3 138株16种新生木 本植物幼苗, 其中杉松和五角枫的新生幼苗个体数 目最多, 分别占新生幼苗总数的 $32.12 \%$ 和 $20.59 \%$ (表2)。东北枫、青楷枫、紫椴、簇毛枫、杉松、五 角枫、千金榆和春榆的新生幼苗数均大于 100 , 而裂 叶榆、胡桃楸、蒙古栋和三花枫的新生幼苗数均在 10以下。总数在2013年达到峰值, 约为2012年新生 幼苗数量的1.2倍和2014年的5倍。紫椴、黄檗和槭 树科植物的幼苗都在2013年出现高峰; 而杉松和春 榆的新生幼苗数量在2012年出现高峰。2012年没有 发现东北枫的新生幼苗。

\section{3 死亡幼苗数量与组成}

中龄林2012-2013年间共有727株幼苗死亡, 分 属于 11 个树种, 死亡数量最多的是水曲柳和杉松, 占总死亡数的 $77.6 \%$, 死亡率最高的是红松, 达到 92.9\% (表2)。2013-2014年, 共有1 435株幼苗死亡, 分属于 15 个树种, 死亡数量最多的依次是水曲柳、 五角枫和东北枫, 共1 202株, 而红松、紫椴、辽椴 和青楷枫的死亡率均达到 $95 \%$ 以上。五角枫、东北 枫和青楷枫在2013-2014年的死亡率远大于20122013年。新生幼苗的死亡数量表明: 2012-2013年死 亡的幼苗中, 新生幼苗占死亡总数的 $51.7 \%$, 杉松 的新生苗死亡数量最多, 占新生苗死亡总数的 $60.1 \%$ (表2)。2013-2014年死亡的幼苗中, 新生幼苗 占死亡总数的 $65.4 \%$, 杉松的新生苗死亡数量最多, 占新生苗死亡总数的 $60.1 \%$; 水曲柳、五角枫和东北 枫等优势种的死亡率达到85\%以上(表2)。

2012-2013年间成熟林共有2 592株幼苗死亡, 分属于 16 个树种, 死亡数量最多的是杉松, 其次是 水曲柳，共1 603株(表2)。2013-2014年, 共有3 821 株幼苗死亡, 分属于 16 个树种, 死亡数量最多的是 五角枫, 共1 332株。2013-2014年幼苗的整体死亡 率明显大于2012-2013年, 而新生苗的整体死亡率 没有明显差异。2012-2013年新生幼苗物种间死亡率 差异很大: 死亡率超过 $90 \%$ 的有 4 个种, 裂叶榆和千 


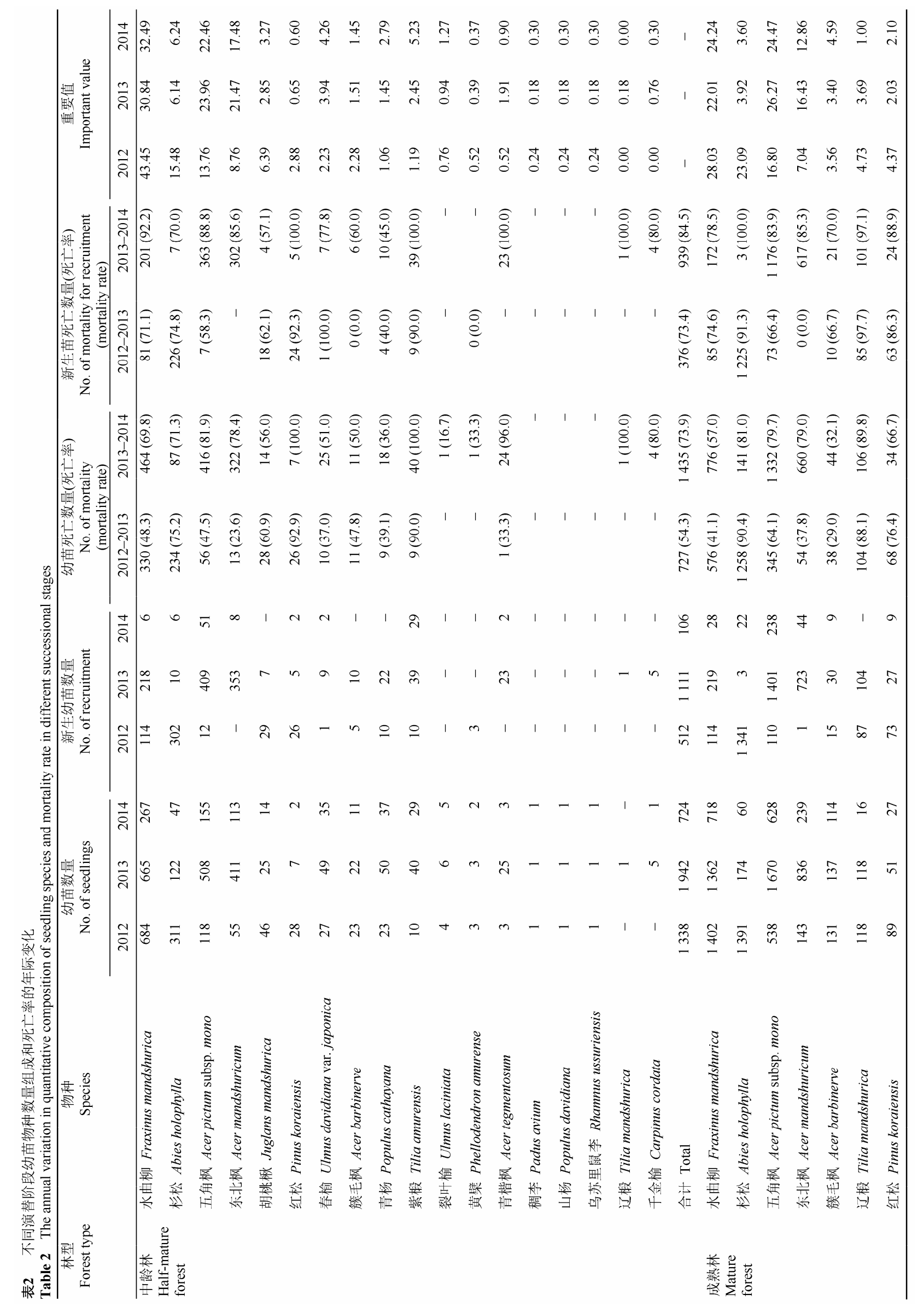




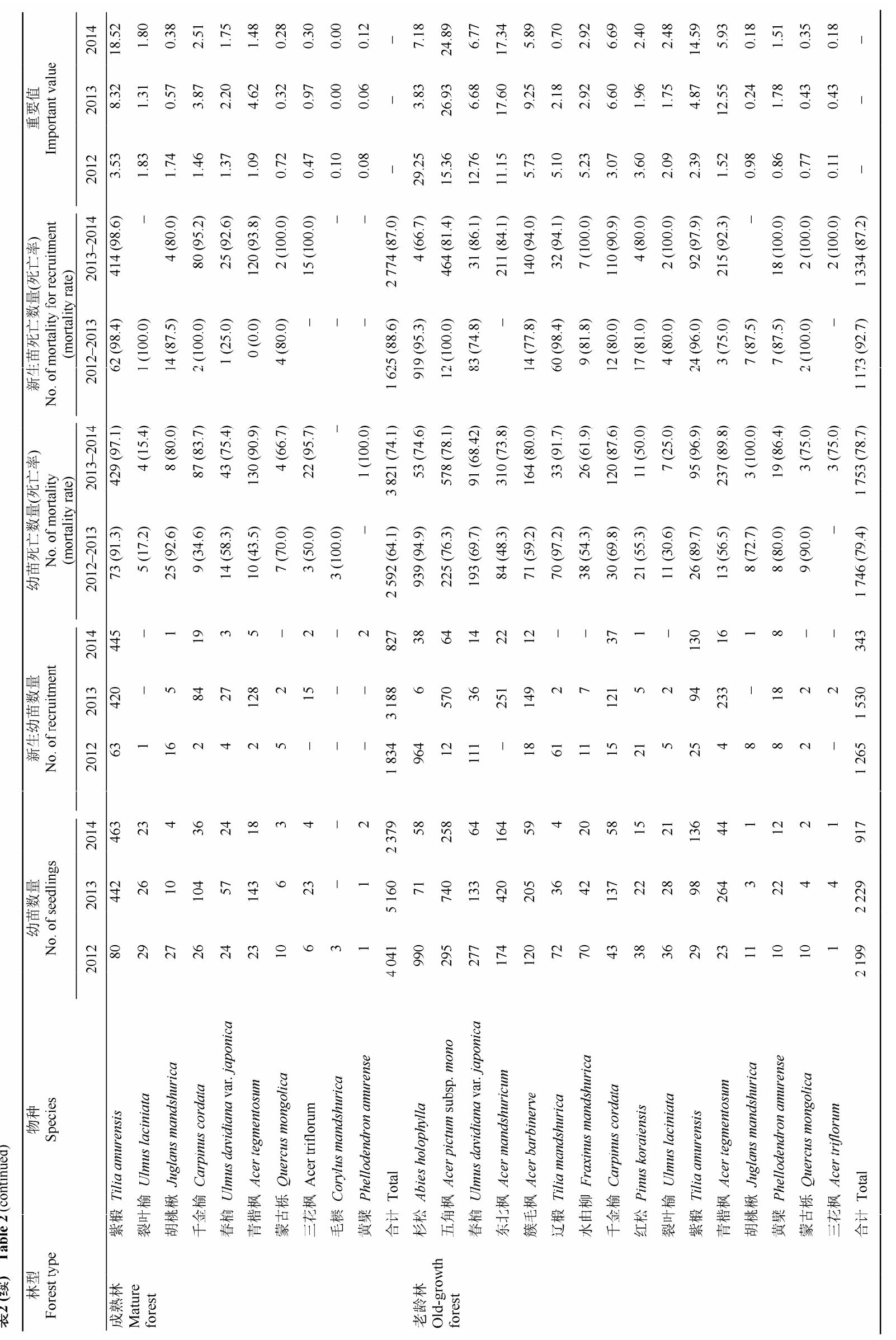

doi: 10.17521/cjpe.2015.0365 
金榆死亡率最高, 其次是杉松和紫椴, 而其他幼苗 的死亡率相对较低(表2)。2013-2014年新生幼苗物 种间死亡率差异并不明显, 均在 $70 \%$ 以上(表2)。

老龄林在两个时间段里分别有 1746 和1 603株 幼苗死亡, 其中新生幼苗比例分别为 $67.2 \%$ 和 $76.1 \%$ (表2)。幼苗死亡率在物种间差异不大, 但在年际间 有明显差异, 2012-2013年杉松及其新生苗死亡率均 高于2013-2014年; 而簇毛枫(Acer barbinerve)、水曲 柳、千金榆、青楷枫、黄檗等物种及其新生苗死亡 率均低于2013-2014年(表2)。

\section{4 幼苗高度级分布}

3 个演替阶段群落中, 木本植物幼苗相对多度主
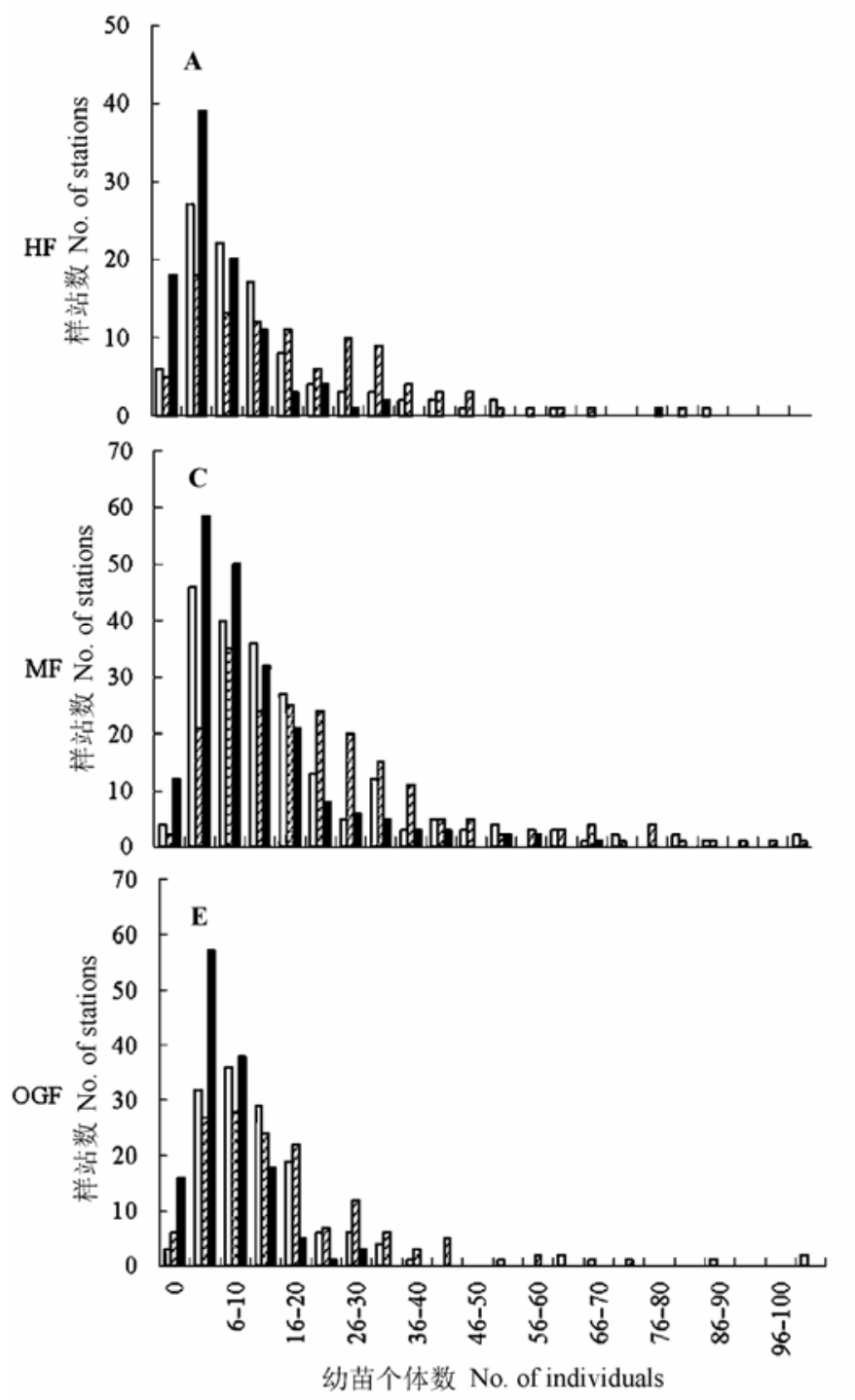

ㅁ2012 घ2013
要集中在0-20 cm高度级间, 并且都呈现出偏峰现 象, 在5-10 cm高度级内最高, 而其他高度级范围内 的幼苗数量很少, 表明该地区木本植物从幼苗到幼 树的发育并不健全，天然更新不良(图3A、3C、3E)。

3 个演替阶段群落中, 木本植物幼苗的丰富度在 不同高度级之间也呈现偏峰现象(图3B、3D、3F)。 3次调查期间, 中龄林幼苗丰富度均在5-10 cm高度 级内最高。成熟林2012年幼苗丰富度在5-10 cm高度 级内最高; 2013年在10-20 cm 高度级丰富度最高; 而2014年在5-10 cm、10-20 cm 和20-30 cm 高度级内 丰富度均为最高。老龄林2012年在10-20 cm高度级 内幼苗丰富度最高; 2013年在5-10 cm 和10-20 cm
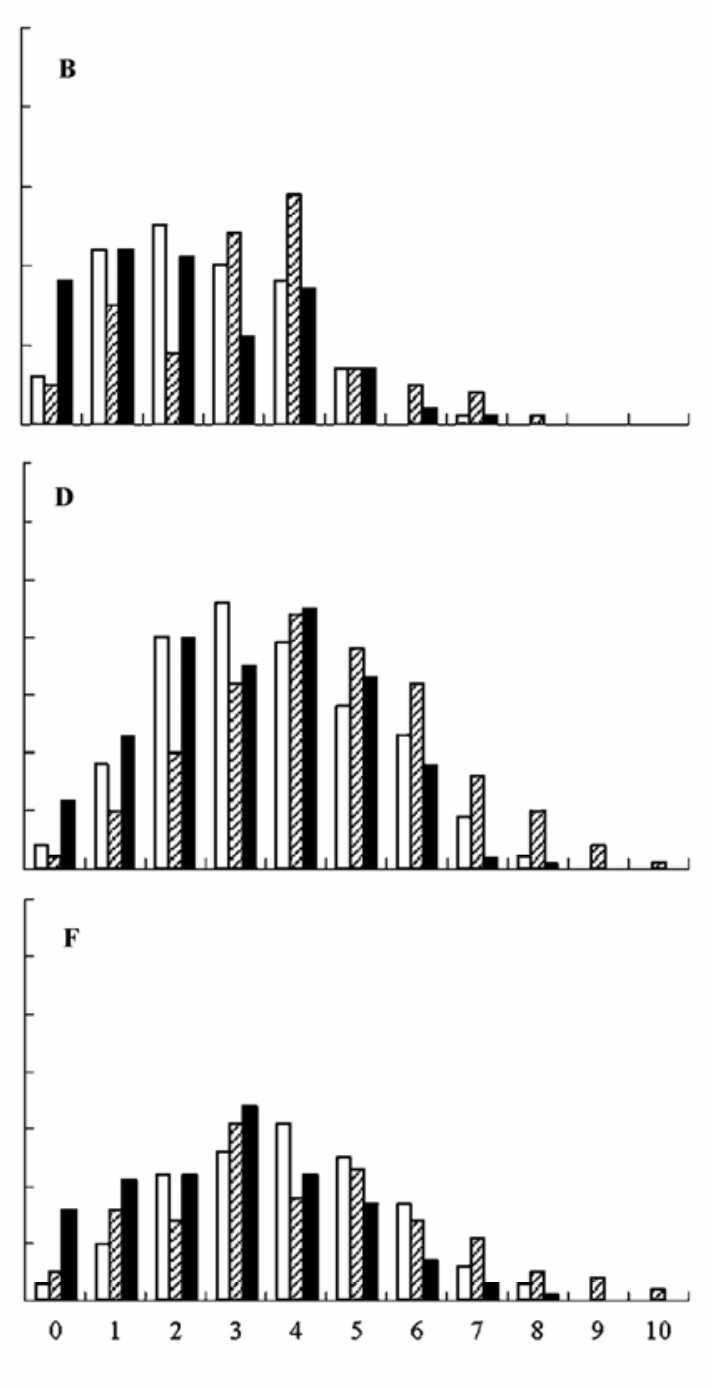

物种数 No. of species

图3 不同演替阶段幼苗相对多度及物种数的高度级分布。HF，中龄林; MF，成熟林; OGF，老龄林。

Fig. 3 Relative abundance and the number of species by height class distribution in different successional stages. HF, half-mature forest; MF, mature forest; OGF, old-growth forest. 
表35个物种幼苗数量与林分类型、20 m内同种成体胸高断面积之和 $(A)$ 和林冠开阔度的多元线性回归结果

Table 3 Results of the multiple linear regression analysis on the seedling abundance of five species against the forest types, the sum of conspecific basal area within $20 \mathrm{~m}(A)$ and canopy openness

\begin{tabular}{|c|c|c|c|c|c|}
\hline 年份 Year & 物种 Species & $C_{\mathrm{MF}}$ & $C_{\mathrm{OGF}}$ & $A$ & 林冠开阔度 Canopy openness \\
\hline \multirow[t]{5}{*}{2013} & 五角枫 Acer pictum subsp. mono & 0.141 & 0.584 & 0.473 & -0.083 \\
\hline & 东北枫 Acer mandshuricum & -0.187 & 0.329 & 0.521 & -0.039 \\
\hline & 水曲柳 Fraxinus mandshurica & -0.059 & -0.589 & 0.214 & -0.010 \\
\hline & 青楷枫 Acer tegmentosum & 0.086 & 0.413 & 0.223 & -0.092 \\
\hline & 紫椴 Tilia amurensis & 0.031 & 0.100 & 0.246 & -0.015 \\
\hline \multirow[t]{5}{*}{2014} & 五角枫 Acer pictum subsp. mono & 0.135 & 0.361 & 0.242 & -0.068 \\
\hline & 东北枫 Acer mandshuricum & -0.031 & 0.281 & 0.265 & 0.035 \\
\hline & 水曲柳 Fraxinus mandshurica & 0.061 & -0.267 & 0.193 & 0.001 \\
\hline & 青楷枫 Acer tegmentosum & 0.021 & 0.274 & 0.140 & -0.067 \\
\hline & 紫椴 Tilia amurensis & 0.208 & 0.237 & 0.301 & -0.005 \\
\hline
\end{tabular}

粗体值表示 $p<0.05$ 。 $C_{\mathrm{MF}}$, 成熟林的幼苗数量相对于中龄林的截距变化; $C_{\mathrm{OGF}}$, 老龄林的幼苗数量相对于中龄林的截距变化。

Values in bold indicate $p<0.05 . C_{\mathrm{MF}}$, change in intercept relative to the half-mature forest in seedlings abundance in the mature forest; $C_{\mathrm{OGF}}$, change in intercept relative to the half-mature forest in seedlings abundance in the old-growth forest.

高度级最高; 而2014年在5-10 cm高度级内丰富度 最高。

\section{5 幼苗数量与同种成体胸高断面积及林冠开阔 度的关系}

2013年, 五角枫、东北枫、水曲柳、青楷枫和 紫椴的幼苗数量在中龄林和成熟林之间没有显著差 异, 但都与 $20 \mathrm{~m}$ 内同种成体胸高断面积之和显著正 相关; 青楷枫幼苗数量与林冠开阔度显著负相关 (表3)。五角枫、东北枫、水曲柳和青楷枫幼苗数量 在中龄林和老龄林之间存在显著差异, 当同种成体 胸高断面积之和相同时, 五角枫、东北枫和青楷枫 在老龄林中的幼苗数量明显高于中龄林, 而水曲柳 在老龄林的幼苗数量明显低于中龄林(表3)。

2014年，五角枫、东北枫、水曲柳、青楷枫和 紫椴幼苗数量都与 $20 \mathrm{~m}$ 内同种成体胸高断面积之 和显著正相关; 五角枫和青楷枫幼苗数量与林冠开 阔度显著负相关(表3)。当同种成体胸高断面积之和 相同时, 五角枫、东北枫、青楷枫和紫椴在老龄林 中的幼苗数量显著高于中龄林, 而水曲柳在老龄林 中的幼苗数量显著低于中龄林; 紫椴幼苗数量随演 替进程的推进逐渐增加(表3)。

\section{3 讨论}

\section{1 树种幼苗的组成特点}

2012至2014年3次调查期间，在蛟河地区3个不 同演替阶段的针阔混交林样地内，分别调查到18、
18 和 17 个种的木本植物幼苗, 明显低于热带雨林 (Turner, 1990; 李晓亮等，2009)和亚热带常绿阔叶 林(Chen et al., 2010)。样地内出现的幼苗种类均在 该样地存在的树种范围内，并没有发现其他树种的 幼苗。而在 3 个样地中均有超过一半的树种幼苗没有 在样地中出现，这可能是由于种群内处于繁殖阶段 的个体数量较少; 或者是由于群落内存在较强的扩 散限制; 另一方面, 种子发芽能力低、幼苗生存力 弱, 以及动物对种子和幼苗的取食也可能导致林下 幼苗缺失(宾粤等, 2011)。中龄林中重要值排在前5 位的乔木树种中, 有 4 个树种幼苗的重要值排在前 5 位; 成熟林和老龄林重要值排在前5位的乔木树种 中, 各有 2 个树种幼苗的重要值排在前 5 位, 表明林 下幼苗的主要物种组成与样地内主要树种组成保持 着一定的相似性，主要树种的幼苗在林下同样保持 着优势地位, 这与以往的研究结果(李晓亮等, 2009; 张健等, 2009; 姚杰等, 2015)一致。

尽管胡桃楸和红松是构成乔木层群落的主要树 种，但是其林下幼苗数量并不多，并且存在明显的 年际差异。这与张健等(2009)和姚杰等(2015)的研究 结果一致, 可能是由于红松和胡桃楸的种子主要依 靠动物传播，这些种子也是啮齿类动物和鸟类的主 要食物来源, 在传播过程中动物对种子的取食对林 下幼苗数量有着重要影响(李俊清和祝宁, 1990); 同 时, 与依靠风力传播的物种相比, 红松和胡桃楸种 子扩散能力较低, 更容易受到病原体和动物的侵害 
(李昕等, 1989), 人类对红松和胡桃楸果实的大量采 摘也极大地减少了到达地面的种子数量(刘足根等, 2004)。而种子的休眠和丰歉年现象也会导致种子和 幼苗数量的年际差异。在本研究中, 胡桃楸的幼苗 密度和死亡率, 特别是新生幼苗的死亡率随演替的 推进逐渐升高, 而红松则表现出相反的趋势。主要 原因可能是植物幼苗在不同光照条件下存活状态有 较大差异。胡桃楸幼苗属阳性物种, 在演替初期数 量较多, 随着演替的推进林冠郁闭度增加, 林下光 环境对胡桃楸幼苗的存活产生明显的抑制作用, 幼 苗数量逐渐趋于下降。而红松幼苗属耐阴性物种, 随着演替的推进, 其优势地位逐渐突出(Davies, 2001; von Breugel et al., 2007)。另外, 2013-2014年 幼苗的整体死亡率明显大于2012-2013年, 这可能是 由于2013年研究地区初次降雪时间比2012年提前半 个月, 造成了大量幼苗的死亡。

\section{2 幼苗高度级结构}

幼苗多度随高度级的变化可以反映出幼苗的年 龄变化, 揭示种群在群落内定居的持续性和种群延 续能力(李帅锋等, 2008)。调查期间3个样地内的幼 苗数量主要集中在5-10 cm之间, 这在一定程度上 反映出新生幼苗的死亡率比其他年龄阶段的死亡率 高, 这与李帅锋等(2008)、Deb和Sundriyal (2008)的 研究结果一致。而在10-20 cm高度级内, 幼苗相对 多度依次为中龄林 $>$ 成熟林 $>$ 老龄林。因此, 尽管中 龄林中幼苗密度较低, 但幼苗存活率明显高于其他 林分, 表明演替初期幼苗的更新能力较强, 随演替 的推进, 幼苗的更新能力逐渐减弱。

从幼苗丰富度来看, 3 个样地内幼苗物种数量主 要集中在5-20 cm之间, 之后随高度级增加而逐渐 减少, 但减少趋势远不及幼苗多度随高度级的变 化。表明在温带森林不同演替阶段的森林群落中, 幼苗个体间的种间竞争和种内的相互作用都是导致 幼苗死亡的重要机制, 而同种幼苗间的相互作用是 导致幼苗死亡的主要原因。这在一定程度上证实了 负密度制约效应在森林更新早期阶段的重要作用 (Comita \& Hubbell, 2009)。

\section{3 幼苗多度的影响因素}

综合分析针阔混交林 5 个主要物种幼苗多度的 影响因子: 林分类型、胸高断面积、种子数量和林 冠开阔度, 结果发现这些因子对 5 个主要物种的幼 苗多度具有明显作用。有研究发现幼苗更新与种子
的多度有关(LePage et al., 1999), 如Harms等(2001) 认为扩散限制使种子不能扩散到距离母树较远的地 区，从而使得群落内物种幼苗呈聚集分布。而 Uriarte等(2005)认为幼苗不能在特定的地点出现不 仅是因为扩散限制, 也可能是由于该地区的环境条 件不适合幼苗定居。例如，宾粤等(2011)研究表明生 态位过程对于样地幼苗种群分布有着重要影响, 因 为每个物种都可利用其他有机体不能利用的资源 (侯继华和马克平, 2002)。在本研究中,水曲柳幼苗在 演替初期数量较多, 青楷枫和紫椴的幼苗数量在演 替后期较多; 青楷枫偏好林冠开阔度较低的生境, 这可能与各树种幼苗的生态位分离有关。

综上所述, 本文研究结果表明温带森林植物群 落林下木本植物幼苗的数量组成和多样性特征与林 分演替阶段有关, 并且表现出明显的年际间差异。 本文在一定程度上证实了负密度制约效应、扩散限 制和生态位过程对幼苗数量组成的影响。尽管这三 个生态过程在幼苗更新过程中并非相互排斥, 但其 相对重要性仍有待进一步探讨和验证。

基金项目 国家“十二五”科技支撑计划项目(2012BAD22B0203)。

致谢 感谢北京林业大学王娟老师、陈贝贝老师和 西弗吉尼亚大学王雨茜博士在工作中给予的帮助。

\section{参考文献}

Bin Y, Ye WH, Cao HL, Huang ZL, Lian JY (2011). Seedling distribution in a subtropical evergreen broad-leaved forest plot in the Dinghu Mountain. Biodiversity Science, 19, 127-133. (in Chinese with English abstract) [宾粤, 叶万 辉, 曹洪麟, 黄忠良, 练琚愉 (2011). 鼎湖山南亚热带 常绿阔叶林20公顷样地幼苗的分布. 生物多样性, 19, 127-133.]

Chen JW, Zhang Q, Li XS, Cao KF (2011). Steady and dynamic photosynthetic responses of seedlings from contrasting successional groups under low-light growth conditions. Physiologia Plantarum, 141, 84-95.

Chen L, Mi XC, Comita LS, Zhang LW, Ren HB, Ma KP (2010). Community-level consequences of density dependence and habitat association in a subtropical broad- leaved forest. Ecology letters, 13, 695-704.

Clark CJ, Poulsen JR, Levey DJ (2012). Vertebrate herbivory impacts seedling recruitment more than niche partitioning or density-dependent mortality. Ecology, 93, 554-564.

Comita LS, Hubbell SP (2009). Local neighborhood and species shade tolerance influence survival in a diverse seedling bank. Ecology, 90, 328-334. 
Comita LS, Uriarte M, Thompson J, Jonckheere I, Canham CD, Zimmerman JK (2009). Abiotic and biotic drivers of seedling survival in a hurricane-impacted tropical forest. Journal of Ecology, 97, 1346-1359.

Connell JH (1971). On the role of natural enemies in preventing competitive exclusion in some marine animals and in rain forest trees. In: den Boer PJ, Gradwell GR eds. Dynamics of Population. Center for Agricultural Publishing and Documentation, Wageningen, The Netherlands. 289-312.

D’Amato AW, Orwig DA, Foster DR (2009). Understory vegetation in old-growth and second-growth Tsuga canadensis forests in western Massachusetts. Forest Ecology and Management, 257, 1043-1052.

Davies SJ (2001). Tree mortality and growth in 11 sympatric Macaranga species in Borneo. Ecology, 82, 920-932.

Deb P, Sundriyal RC (2008). Tree regeneration and seedling survival patterns in old-growth lowland tropical rainforest in Namdapha National Park, northeast India. Forest Ecology and Management, 255, 3995-4006.

Guo QJ (2013). Effects of Selection and Prescribed Fire Disturbances on Longleaf Pine Seedling Regeneration. $\mathrm{PhD}$ dissertation, Northwest A\&F University, Yangling, Shaanxi. 2-3. (in Chinese with English abstract) [郭秋菊 (2013). 择伐和火干扰对长叶松幼苗更新的影响. 博士 学位论文, 西北农林科技大学, 陕西杨凌. 2-3.]

Harms KE, Condit R, Hubbell SP, Foster RB (2001). Habitat associations of trees and shrub in a 50-ha neotropical forest plot. Journal of Ecology, 89, 947-959.

Harms KE, Wright SJ, Calderon O, Hernandez A, Herre EA (2000). Pervasive density-dependent recruitment enhances seedling diversity in a tropical forest. Nature, 404, 493-495.

Hou JH, Ma KP (2002). On mechanisms of species coexistence in plant communities. Acta Phytoecologica Sinica, 26, 1-8. (in Chinese with English abstract) [侯继华, 马克平 (2002). 植物群落物种共存机制的研究进展. 植物生态 学报, 26, 1-8.]

Jansen PA, Visser MD, Wright SJ, Rutten G, Muller-Landau HC, Rejmanek M (2014). Negative density dependence of seed dispersal and seedling recruitment in a neotropical palm. Ecology letters, 17, 1111-1120.

Janzen DH (1970). Herbivores and the number of tree species in tropical forests. The American Society of Naturalists, 104, 501-528.

Kang B, Liu SR, Wang DX, Zhang Y, Liu HR, Du YL (2011). Regeneration characteristics of woody plant seedlings in typical secondary forests in Qinling Mountains. Chinese Journal of Applied Ecology, 22, 3123-3130. (in Chinese with English abstract) [康冰, 刘世荣, 王得祥, 张荣, 刘 红茹, 杜焰玲 (2011). 秦岭山地典型次生林木本植物幼 苗更新特征. 应用生态学报, 22, 3123-3130.]

Kang B, Wang DX, Li G, Gao YX, Zhang Y, Du YL (2012).
Characteristics of seedlings regeneration in Quercus aliena var. acuteserrata secondary forests in Qinling Mountains. Acta Ecologica Sinica, 32, 2738-2747. (in Chinese with English abstract) [康冰, 王得祥, 李刚, 高妍夏, 张莹, 杜焰玲 (2012). 秦岭山地锐齿栋次生林幼苗更新特征. 生态学报, 32, 2738-2747.]

Lebrija-Trejos E, Wright SJ, Hernandez A, Reich PB (2014). Does relatedness matter? Phylogenetic density-dependent survival of seedlings in a tropical forest. Ecology, 95, 940-951.

LePage PT, Canham CD, Coates KD, Bartemucci P (1999). Seed abundance versus substrate limitation of seedling recruitment in northern temperate forests of British Columbia. Canadian Journal of Forest Research, 30, 415-427.

Li JQ, Zhu N (1990). Population structure of Korean pine and its dynamics. Journal of Ecology, 9, 6-10. (in Chinese with English abstract) [李俊清, 祝宁 (1990). 红松的种 群结构与动态过程. 生态学杂志, 9, 6-10.]

Li SF, Liu WD, Su JR, Zhang JR, Liu QY (2008). Woody seedling regeneration in secondary succession of monsoon broad-leaved evergreen forest in Puer, Yunnan, Southwest China. Acta Ecologica Sinica,18, 5653-5662. (in Chinese with English abstract) [李帅锋, 刘万德, 苏建荣, 张志 钧, 刘庆云 (2008). 普洱季风常绿阔叶林次生演替中木 本植物幼苗更新特征. 生态学报, 18, 5653-5662.]

Li X, Xu ZB, Tao DL (1989). Natural regeneration of Korean pine in broad-leaved Korean pine stands Fenglin Natural Reserve of Xiaoxing' anling. Journal of Northeast Forestry University, 17(6), 1-7. (in Chinese with English abstract) [李听, 徐振邦, 陶大立 (1989). 小兴安岭丰林自然保 护区阔叶红松林红松天然更新研究. 东北林业大学学 报, 17(6), 1-7.]

Li XL, Wang H, Zheng Z, Lin LX, Deng XB, Cao M (2009). Composition, spatial distribution and survival during the dry season of tree seedlings in a tropical forest in Xinshuangbanna, SW China. Chinese Journal of Plant Ecology, 33, 658-671. (in Chinese with English abstract) [李晓 亮, 王洪, 郑征, 林露湘, 邓晓保, 曹敏 (2009). 西双版 纳热带森林树种幼苗的组成、空间分布和旱季存活. 植 物生态学报, 33, 658-671.]

Li XS, Liu WY, Chen JW, Yuan CM (2009). Seedling regeneration in primary moist evergreen broad-leaved forest and different types secondary vegetations in Ailao Mountains. Chinese Journal of Ecology, 28, 1921-1927. (in Chinese with English abstract) [李小双, 刘文耀, 陈军 文, 袁春明 (2009). 哀牢山湿性常绿阔叶林及不同类型 次生植被的幼苗更新特征. 生态学杂志, 28, 19211927.]

Li XS, Peng MC, Dang CL (2007). Research progress on natural regeneration of plants. Chinese Journal of Ecology, 26, 
2081-2088. (in Chinese with English abstract) [李小双, 彭明春, 党承林 (2007). 植物自然更新研究进展. 生态 学杂志, 26, 2081-2088.]

Li Y, Tao JP, Wang YJ, Yu XH, Xi Y (2007). Effects of Fargesia nitida on regeneration of Abies faxoniana seedlings near the edge of subalpine dark coniferous forest. Journal of Plant Ecology (Chinese Version), 31, 283-290. (in Chinese with English abstract) [李媛, 陶建平, 王永健, 余小 红, 席一 (2007). 亚高山暗针叶林林缘华西箭竹对岷江 冷杉幼苗更新的影响. 植物生态学报, 31, 283-290.]

Lin LX, Comita LS, Zheng Z, Cao M (2012). Seasonal differentiation in density-dependent seedling survival in a tropical rain forest. Journal of Ecology, 100, 905-914.

Liu ZG, Ji LZ, Hao ZQ, Zhu JJ, Kang HZ (2004). Effect of cone-picking on natural regeneration of Korean pine in Changbai Mountain Nature Reserve. Chinese Journal of Applied Ecology, 15, 958-962. (in Chinese with English abstract) [刘足根, 姬兰柱, 郝占庆, 朱教君, 康宏樟 (2004). 松果采摘对长白山自然保护区红松天然更新的 影响. 应用生态学报, 15, 958-962.]

Nilsen ET, Walker JF, Miller OK, Semones SW, Lei TT, Clinton BD (1999). Inhibition of seedling survival under Rhododendron maximum (Ericaceae): Could allelopathy be a cause? American Journal of Botany, 86, 1597-1605.

Peng SJ, Huang ZL, Peng SL, Ouyang XJ, Xu GL (2004). Factors influencing mortality of seed and seedling in plant nature regeneration process. Guihaia, 24, 113-121. (in Chinese with English abstract) [彭闪江, 黄忠良, 彭少麟, 欧阳学军, 徐国良 (2004). 植物天然更新过程中种子和 幼苗死亡的影响因素. 广西植物, 24, 113-121.]

Rüger N, Huth A, Hubbell SP, Condit R (2009). Response of recruitment to light availability across a tropical lowland rain forest community. Journal of Ecology, 97, 13601368.

Shang ZH, Long RJ, Ma YS, Ding LM (2008). Spatial heterogeneity and similarity of adult plants and seedlings in "black soil land” secondary weed community, QinghaiTibetan Plateau. Journal of Plant Ecology (Chinese Version), 32, 1157-1165. (in Chinese with English abstract) [尚占环, 龙瑞军, 马玉寿, 丁路明 (2008). 青藏高原 “黑土滩”次生毒杂草群落成体植株与幼苗空间异质性 及相似性分析. 植物生态学报, 32, 1157-1165.]

Su Y, Jiao JY, Wang ZJ (2014). Characteristics of seedling survival in habitats of hill and gully slopes in hill-gully Loess Plateau region of northern Shaanxi. Chinese Journal of Plant Ecology, 38, 694-709. (in Chinese with English abstract) [苏嫄, 焦菊英, 王志杰 (2014). 陕北黄土丘陵 沟壑区坡沟立地环境下幼苗的存活特征. 植物生态学 报, 38, 694-709.]

Szwagrzyk J, Szewczyk J, Bodziarczyk J (2001). Dynamics of seedling banks in beech forest: Results of a 10-year study on germination, growth and survival. Forest Ecology and Management, 141, 237-250.

Teegalapalli K, Hiremath AJ, Jathanna D (2010). Patterns of seed rain and seedling regeneration in abandoned agricultural clearings in a seasonally dry tropical forest in India. Journal of Tropical Ecology, 26, 25-33.

Turner IM (1990). Tree seedling growth and survival in a Malaysian rain forest. Biotropica, 22, 146-154.

Uriarte M, Canham CD, Thompson J, Zimmerman JK, Brokaw $N$ (2005). Seedling recruitment in a hurricane-driven tropical forest: Light limitation, density-dependence and the spatial distribution of parent trees. Journal of Ecology, 93, 291-304.

von Breugel M, Bongers F, Martínez-Ramos M (2007). Species dynamics during early secondary forest succession: Recruitment, mortality and species turnover. Biotropica, 35, 610-619.

Wang CH, Li JQ, Chen FQ, Yang Y (2011). Factors affecting seedling regeneration of Liquidambar formosana in the $L$. formosana forests in hilly regions of Southeast Hubei, China. Chinese Journal of Plant Ecology, 35, 187-194. (in Chinese with English abstract) [王传华, 李俊清, 陈芳清, 杨荣 (2011). 鄂东南低丘地区枫香林下枫香幼苗更新 限制因子. 植物生态学报, 35, 187-194.]

Willand JE, Baer SG, Gibson DJ, Klopf RP (2013). Temporal dynamics of plant community regeneration sources during tallgrass prairie restoration. Plant Ecology, 214, 11691180.

Yan Y, Zhang C, Wang Y, Zhao X, von Gadow K (2015). Drivers of seedling survival in a temperate forest and their relative importance at three stages of succession. Ecology and Evolution. 5, 4287-4299.

Yao J, Yan Y, Zhang CY, Pi TH, Zhao XH (2015). Composition and monthly dynamics of tree seedlings in a coniferous and broad-leaved mixed forest in Jiaohe, Jilin Province, China. Chinese Journal of Plant Ecology, 39, 717725. (in Chinese with English abstract) [姚杰, 间琰, 张春 雨, 䂙田辉, 赵秀海 (2015). 吉林蛟河针阔混交林乔木 幼苗组成与月际动态. 植物生态学报, 39, 717-725.]

Yin HJ, Cheng XY, Lai T, Lin B, Liu Q (2011). Seed rain, soil seed bank and seedling regeneration in a 65-year Picea asperata plantation in subalpine coniferous, western Sichuan, China. Chinese Journal of Plant Ecology, 35, 35-44. (in Chinese with English abstract) [尹华军, 程新 颖, 赖挺, 林波, 刘庆 (2011). 川西亚高山65年人工云 杉林种子雨、种子库和幼苗定居研究. 植物生态学报, 35, 35-44.]

Yu F, Shi XX, Chen LL, Huang QP, Song B (2013). Species composition and regeneration characteristics of main woody plant seedlings in a pine-oak mixed forest in Qinling Mountains. Acta Botanica Boreali-Occidentalia

www.plant-ecology.com 
Sinica, 33, 592-598. (in Chinese with English abstract) [于 飞, 史晓晓, 陈莉莉, 黄青平, 宋彬 (2013). 秦岭山地 松栎混交林主要木本植物组成及更新特征. 西北植物 学报, 33, 592-598.]

Yu XY, Li YH (2010). Characteristics of woody plant regeneration in karren-habitats successional plant communities in Yunnan Shilin karst area of China. Chinese Journal of Plant Ecology, 34, 889-897. (in Chinese with English abstract) [俞䈗押, 李玉辉 ( 2010). 滇石林喀斯特植物群 落不同演替阶段的溶痕生境中木本植物的更新特征. 植物生态学报, 34, 889-897.]
Zhang J, Li BH, Bai XJ, Yuan ZQ, Wang XG, Ye J (2009). Composition and interannual dynamics of tree seedlings in broad-leaved Korean pine (Pinus koraiensis) mixed forest in Changbai Mountain. Chinese Biodiversity, 17, 385-396. (in Chinese with English abstract) [张健, 李步杭, 白雪 娇, 原作强, 王绪高, 叶吉 (2009). 长白山阔叶红松林 乔木树种幼苗组成及其年际动态. 生物多样性, 17, 385-396.]

责任编委: 郝占庆 责任编辑: 王 蒇

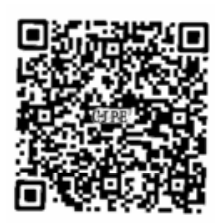

植物生态学报官网

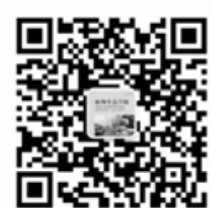

微信订阅号

期刊及学科

相关信息发布

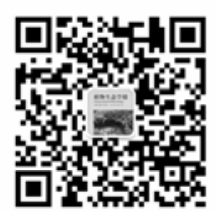

微信服务号

稿件状态查询

全文检索测览 